\title{
O conceito de documento em abordagem bibliográfica segundo as disciplinas constituintes do campo
}

\author{
The concept of document in the bibliographic approach according to the constituent \\ disciplines of the field
}

\begin{abstract}
Cristina Dotta Ortega
Doutora em Ciência da Informação pela Escola de Comunicações e Artes da Universidade de São Paulo -

ECA/USP.

Professora Adjunta na Escola de Ciência da Informação da Universidade Federal de Minas Gerais - ECI/UFMG.

E-mail: ortega@eci.ufmg.br
\end{abstract}

\begin{abstract}
Resumo
Bibliografia, Biblioteconomia, Documentação e Ciência da Informação apresentam, cada uma a seu modo, e influenciando-se uma à outra, o campo que tem por objeto a mediação documentária em abordagem bibliográfica. Na perspectiva de vertentes constituintes do campo, estas disciplinas permitem um conceito de documento no sentido de objeto empírico sobre o qual recaem os procedimentos. O objetivo é tratar da construção do conceito de documento por meio das disciplinas cujas contribuições convergem para o campo das ações de mediação documentária em abordagem bibliográfica. Como metodologia, recorreu-se à exploração de literatura que discute o documento pelas disciplinas citadas, buscando estabelecer equivalências e realizar contrapontos. O primeiro tópico apresenta uma construção histórica do conceito de documento em Documentação, durante o século XX, em especial, em solo francês, desde sua concepção por Paul Otlet, depois por Suzanne Briet, e posteriormente por Jean Meyriat; o segundo tópico perpassa as disciplinas Bibliografia, Biblioteconomia e Documentação, em torno do conceito de documento em perspectiva empírica ou científica, e a Ciência da Informação no que tange aos aspectos que herda das disciplinas que a precederam; e o terceiro tópico busca aprofundar o conceito de documento, em abordagem bibliográfica, estabelecendo algumas relações com ideias propostas para este conceito em abordagem arquivística e museológica. Conclui que predomina abordagem bibliográfica sobre documento que enfatiza a instância tipológica do objeto e normatizadora de sua descrição, menos que aquela baseada no caráter simbólico dos procedimentos e de seu produto final.
\end{abstract}

Palavras-chave: Abordagem bibliográfica do documento. Documentação. Biblioteconomia. Bibliografia. Ciência da Informação.

\begin{abstract}
Bibliography, Library Science, Documentation and Information Science present, each in their own way and influencing one another, the field that is engaged in documentary mediation in the bibliographic approach. In view of the constituent parts of the field, these disciplines enable a concept of document in the sense of empirical object on which falls the procedures. The objective is to treat the construction of the concept of document by means of the disciplines whose contributions converge in the field of documentary mediation actions in the bibliographic approach. The methodology employed was a search of the literature that discusses the document in the aforementioned disciplines to seek to establish equivalences and perform counterpoints. The first part provides a historical construction of the concept of document during the twentieth century, in particular on French soil, from its conception by Paul Otlet, then by Suzanne Briet, and then by Jean Meyriat; the second part intersects the disciplines of Bibliography, Library Science and Documentation around the concept of document from an empirical or scientific perspective, and the aspects that Information Science inherited from the disciplines that preceded it; and the third part, which seeks to deepen the concept of document in the bibliographic approach by establishing some relationships with ideas proposed for this concept by archival and museological approaches. It is concluded that the predominant bibliographic approach to the document emphasizes the typological instance of the object and the normalizing of its description, unless that is based on the symbolic character of procedures and of the final product.
\end{abstract}

Keywords: Bibliographic approach to document. Documentation. Library Science. Bibliography. Information Science.

InCID: R. Ci. Inf. e Doc., Ribeirão Preto, v. 7, n. esp., p. 41-64, ago. 2016.

DOI: 10.11606/issn.2178-2075.v7iespp41-64 


\section{Introdução}

Bibliografia, Biblioteconomia, Documentação e Ciência da Informação desenvolveram-se no tempo por meio da ênfase em um ou outro aspecto, a depender de contingências políticas e culturais, além de técnicas e tecnológicas, de cada época e lugar, apresentando entre si distanciamentos, convergências e aproveitamentos. Essas disciplinas contemplam, cada uma a seu modo, e influenciando-se uma à outra, o campo que tem por objeto a mediação documentária em abordagem bibliográfica. As ações de mediação são realizadas concretamente por meio de procedimentos específicos, na forma de proposição de mensagens, entre objetos e pessoas no contexto das atividades em que estas estão envolvidas. O objetivo do campo é o da apropriação dos conteúdos pelos sujeitos que foram destinatários das mensagens produzidas. Os procedimentos são realizados de modo a colocar o objeto em um outro lugar (simbólico), implicando transformação que conduziu à denominação própria, qual seja, documento. Na perspectiva de vertentes constituintes do campo, essas disciplinas permitem um conceito de documento, no sentido do objeto empírico sobre o qual recaem os procedimentos.

O objetivo deste trabalho é o de tratar da construção do conceito de documento por meio das disciplinas cujas contribuições convergem para o campo das ações de mediação documentária em abordagem bibliográfica. A proposta se justifica uma vez que, em campos aplicados, ou seja, voltados à formulação de soluções a demandas sociais, o estudo dos objetos empíricos é condição necessária ao seu desenvolvimento.

Como metodologia, recorreu-se à exploração de literatura que discute o documento pelas disciplinas citadas, buscando estabelecer equivalências e realizar contrapontos. Em função do acúmulo decorrente do conhecimento subjacente à prática profissional e do conhecimento acadêmico, pode-se falar em campo próprio, ou seja, singular, mas não é possível discorrer sobre ele sem estudar as vertentes que o constituíram e que, de algum modo, explicam suas contínuas segmentações. Estudos realizados no âmbito destas disciplinas que não respondem pela historicidade das ações de mediação documentária foram desconsiderados, uma vez que, metodologicamente, tanto olhares convergentes quanto divergentes contribuem para a construção de um conceito, mas disso depende que haja algum nível de compartilhamento de questões. 
A estrutura do trabalho foi elaborada como segue. O primeiro tópico trata de uma construção histórica do conceito de documento, para o que foi privilegiada a proposta da Documentação, por Paul Otlet, na Bélgica, do final do século XIX para o XX, com desenvolvimento neste período e depois, na França, com Suzanne Briet, da Biblioteca Nacional e, mais tarde, com Jean Meyriat, no contexto dos estudos em torno da denominada Ciências da Informação e Comunicação (Sciences de l'Information et de la CommunicationSIC). A busca por um termo genérico relativo ao objeto em questão, independente de sua diversidade tipológica ou suporte material, e a constatação do desenvolvimento do conceito durante o século XX, justificam essa escolha. O segundo tópico perpassa as disciplinas Bibliografia, Biblioteconomia e Documentação, em torno do conceito de documento em perspectiva empírica ou científica, e a Ciência da Informação no que tange aos aspectos herdados das disciplinas que a precederam. O terceiro e último tópico busca aprofundar o conceito de documento em abordagem bibliográfica, estabelecendo algumas relações com o documento em abordagem arquivística e museológica, a partir das categorias documento por intenção e documento por atribuição.

\section{Construção histórica do conceito de documento}

Segundo desenvolvemos anteriormente (ORTEGA; LARA, 2010), é no contexto da proposta da Documentação, na passagem do século XIX para o XX, em especial pelo belga Paul Otlet, que o conceito de documento é trabalhado como tal, por indicar maior capacidade de generalização. Junto com Henri Lafontaine, Otlet preocupa-se com a necessidade de um controle bibliográfico universal que, ao fornecer informação a todos, funcionaria como instrumento que conduziria ao respeito mútuo e à paz entre os povos. Otlet, em seu Traité de Documentation, publicado em 1934, ressalta a Bibliografia como descrição de documentos, mas defende a Bibliologia, que de modo relacionado, representava uma ciência e uma técnica gerais do documento (OTLET, 1996, p. 9). Segundo Fayet-Scribe (2001, p. 52), nos artigos publicados entre 1905 e 1917, Otlet foi abandonando a palavra bibliografia em proveito das palavras documentação e informação, e no Traité, ele fez uso da palavra Documentologia para designar o campo do conhecimento que propõe ultrapassando as palavras Bibliografia, Bibliologia e Documentação.

Otlet propõe uma grande mudança de perspectiva quando desenvolve a ideia de que tudo pode ser um documento. Ele apresenta os documentos a partir da diversidade de objetos 
e ambientes existentes, ressaltando, por exemplo, os documentos audiovisuais que estavam em franco desenvolvimento no século XIX. Livro e documento constituem para ele "um suporte de uma certa matéria e dimensão (...) em que se incluem signos representativos de certos dados intelectuais (OTLET, 1996, publicação original de 1934, p. 43). Segundo Sagredo Fernández e Izquierdo Arroyo (1983, p. 305), Otlet adota a forma 'livro ou documento', mantendo a primeira palavra apenas em regime de conservação dos usos. Considera os livros, no entanto, como termo genérico para manuscritos e impressos de toda espécie, constituindo em seu conjunto a memória materializada da humanidade, por excelência, os órgãos da conversação, da concentração e da difusão do pensamento, devendose considerá-los como instrumentos de pesquisa, de cultura, de ensino, de informação e de recreio, pois são o receptáculo e o meio de transportes das ideias (p. 43).

Suzanne Briet, bibliotecária da Biblioteca Nacional da França e considerada discípula de Otlet, trata do conceito na perspectiva anterior, mas agora no contexto do pós-Segunda Guerra Mundial, em sua pequena obra Qu'est-ce que la documentation?, publicada em 1951. Adota a expressão 'produção documentária' (BRIET, 1951, p. 24-25) para indicar a produção de documentos secundários pelas organizações de documentação a partir dos documentos iniciais (os quais seriam criados pelos autores e conservados pelas organizações de documentação). Assim, após a afirmação de Otlet de que tudo pode ser um documento e de sua caracterização como matéria e conteúdo, Briet estabelece algumas condições para que um objeto seja considerado documento, por meio das perguntas: Uma estrela é um documento? Um seixo levado pela torrente é um documento? Um animal vivo é um documento? Briet responde que não, pois apenas o são as fotografias e os catálogos das estrelas, as pedras de um museu de mineralogia, os animais catalogados e expostos num zoológico (p. 7). O exemplo é mais desenvolvido na sua famosa explanação sobre o antílope encontrado na África, cuja informação é divulgada na imprensa e comunicada na Academia de Ciências, o animal é colocado no jardim zoológico e catalogado, quando morto é empalhado e conservado no museu, a seu respeito faz-se uma primeira monografia, depois compondo uma enciclopédia especializada, e então uma enciclopédia geral, ambas catalogadas numa biblioteca. Briet afirma que o antílope catalogado é um documento original e os outros documentos são secundários ou derivados (p. 7-8). As condições de representação e de mudança de lugar original do objeto permitem entender a ideia de Briet, mas nos leva a questionar a necessária mudança de lugar geográfico, já que se trata antes da proposição de um lugar simbólico ao 
objeto por meio de procedimentos de significação. Como exemplo, uma fotografia não pode ser considerada um documento por ela mesma, pois depende dos procedimentos citados.

Atribuímos a terceira contribuição para a construção do conceito de documento ao grupo de pesquisadores formado na década de 1970 em torno de questões de leitura, comunicação e documentação, compondo o campo das Ciências da Informação e da Comunicação, na França. Simultaneamente, na década de 1980, autores espanhóis como Sagredo e Izquierdo, entre outros, desenvolveram concepções semelhantes, em que se enfatiza o papel do uso do documento como tal e incorpora-se a questão da utilidade do documento. A literatura espanhola é tributária da construção francesa do termo documento, apresentando construção peculiar sobre Documentação, entre outros por considerá-la em sua relação com a produção científica. Podemos dizer que a noção de documento proposta pelos primeiros documentalistas (Otlet e Briet) foi aprofundada e atualizada pelos pesquisadores franceses e espanhóis nas décadas seguintes.

O grupo original das Ciências da Informação e da Comunicação tem em Robert Escarpit um de seus principais representantes. Em obra originalmente publicada em 1976 (ESCARPIT, 1991, p. 123-126), define o documento como um objeto informacional visível ou palpável, dotado de uma dupla independência com relação ao tempo: a sincronia e a estabilidade. A sincronia se refere à independência interna da mensagem, não como uma sequência linear de eventos, mas uma justaposição multidimensional de traços, enquanto a estabilidade é observada na independência global do objeto informacional, não no sentido de um evento inscrito na passagem do tempo, mas de um suporte material do traço que pode ser conservado, transportado e reproduzido. Se um evento se produz, um documento foi produzido, existe, é conhecido e previsível. Para Escarpit, o documento se explica por ser suscetível de uma leitura, ou seja, de uma exploração em função de um projeto a realizar, conduzindo não apenas a uma reativação do evento, mas a uma produção informacional nova.

Mas é Jean Meyriat quem se debruça sobre o documento, em artigo fundador do conceito na perspectiva das ações de mediação documentária. $\mathrm{O}$ autor organiza a questão do 'ser documento' em duas categorias, posteriormente formuladas como documento por intenção e documento por atribuição.

Meyriat (1981, p. 51) parte do entendimento de que uma definição de documento depende das noções que cobrem seus termos derivados, relacionando-se, portanto, com os pontos de vista e os métodos da Documentação e da Documentologia. De modo similar à 
O conceito de documento em abordagem bibliográfica segundo as disciplinas constituintes do campo

definição de Otlet quanto à matéria e aos dados intelectuais, para Meyriat, as duas noções são inseparáveis uma da outra, e sua conjunção é essencial nesta definição, sendo uma de natureza material (o objeto que serve de suporte) e a outra conceitual (o conteúdo da comunicação, isto é, a informação). Para ele, o documento pode ser definido como um objeto que suporta a informação, que serve para comunicar (sendo que a comunicação pode ser repetida) e que é durável. Servir para comunicar não é característica inerente, de tal modo que o documento pode ser todo e qualquer objeto (como colocou Otlet), mas o mesmo deve estar encarregado da função de transmitir uma mensagem (p. 52). O lugar simbólico, e não o lugar físico, é necessário ao documento, a despeito dos exemplos elucidativos de Briet: não é necessário sequer que os objetos sejam reunidos para informar, como no caso do arqueólogo que utiliza como documento os objetos que ele descobre em seu lugar de pesquisa, porque eles lhe fornecem informações sobre os grupos humanos que os fabricaram e utilizaram (p. 52).

A compreensão do conceito de documento implica, segundo Meyriat (1981), que a documentação constitui um sistema técnico-social, no sentido de um conjunto de elementos ligados entre si de modo a serem interdependentes e arranjados com vistas a alcançar um objetivo, o de obter informação. O sistema técnico-social é composto pelos seguintes elementos: seres humanos, essencialmente as pessoas ou grupo de pessoas que buscam informação e eventualmente seus auxiliares ou intermediários; os objetos materiais, os documentos e as ferramentas ou máquinas empregadas para tratar estes documentos; e os processos ou "savoir faire" técnicos necessários a este tratamento (p. 57). Meyriat discorre sobre o objeto da disciplina, concluindo que "todos os elementos do sistema técnico-social da documentação e as inter-relações que os unem são objetos privilegiados para nossa disciplina" (p. 58).

A partir da ideia de que todo objeto pode tornar-se documento, Meyriat (1981) propõe distinguir os objetos que são projetados desde a origem para fornecer informação, como os cartazes ou fitas magnéticas, e aqueles que são encarregados de desempenhar este papel depois ou subsidiariamente (p. 52). Segundo Meyriat, a comunicação pressupõe o emissor e o receptor da mensagem, ambos habilitados a fornecer-lhe uma significação, o que resulta em duas situações diferentes: em uma delas, emissor e receptor fornecem a significação conjuntamente em um acordo prévio entre um e outro sobre a informação atribuída ao documento, como quando um especialista escreve um artigo destinado a ser lido por outros especialistas do mesmo ramo; na outra, o documento foi produzido, por 
exemplo, para uma função estética. O autor explica que, nas duas situações, a função atribuída será necessária, pois a vontade de obter uma informação é elemento necessário para que um objeto seja considerado documento, apesar de a vontade de seu criador ter sido outra (p. 5253). De outro modo, afirma que "o documento não é um dado, mas o produto de uma vontade, aquela de informar ou se informar - a segunda ao menos sendo sempre necessária" (p. 54). Meyriat considera ainda que "esse papel ativo do receptor pode modificar no tempo a função informativa de um mesmo objeto" e que a capacidade informativa do documento não é esgotada pelos usos já realizados (p. 53).

Tomando como base Meyriat (1981) e contemporâneos, o documento é: objeto produzido ou não com intenção de ser documento (produção do documento); e objeto que pode funcionar como documento, pois seu uso como tal é que determina que assim o seja (uso do documento). Além disso, a função de informação do documento pode mudar no tempo (uso do documento no tempo). Deste modo, um documento produzido com esta intenção não é definitivo para uma situação de 'ser documento' pois disso depende que o mesmo seja abordado enquanto tal, assim como, abordagens iniciais são reformuladas no decorrer do tempo.

Meyriat discorre sobre a categoria documento por intenção no contexto da disciplina de que trata. Considera que há objetos que têm em comum o fato de serem documentos, ao menos virtualmente falando. Dito de outro modo, os documentos produzidos para comunicar aos destinatários uma mensagem informativa são destinados a ser documentos. A filmologia, iconologia, discologia, bibliologia, e outras, são voltadas a estudar tipos específicos de documentos, enquanto paralelamente, o conhecimento descritivo dos objetos produzidos pelo sistema correspondente é realizado, respectivamente, pela filmografia, discografia, iconografia, bibliografia. Meyriat retoma o termo Documentologia no sentido de uma generalização das disciplinas anteriormente nomeadas, que se ocupa do estudo do sistema de produção e distribuição de todos os documentos por intenção, independentemente de sua utilização, documentária ou outra. Assim, entende que a Documentologia é um discurso científico sobre as categorias de documentos, sobre as quais não há um discurso particular, como no caso das disciplinas específicas. Por sua vez, a documentografia designa o estudo enumerativo, descritivo e classificador de todo tipo de documento (MEYRIAT, 1981, p. 59-60). 
O conceito de documento em abordagem bibliográfica segundo as disciplinas constituintes do campo

Segundo Couzinet, Régimbeau e Courbières (2001, p. 467-506), o conceito proposto por Meyriat foi desenvolvido por Fondin, em 1995, sob os termos documento por intenção e documento por atribuição, os quais hoje estão incorporados à produção científica francesa. Para uma precisão do termo documento por intenção, o próprio Meyriat retoma a questão e a desenvolve 25 anos depois. Para Meyriat (2006, p. 12), como todo produto da atividade humana, o documento surge no lugar (imaterial) e no momento em que se reencontram os diversos sistemas sociais ou técnico-sociais de que é derivado. O documento por intenção, no entanto, é somente aquele especialmente produzido para veicular a informação, de tal modo que, se o autor produz um livro ou um artigo, o documentalista legitima este livro ou artigo como documento, inserindo-o em processos de circulação, por meio de atividades que se articulam às de outros grupos, como editores e livreiros. Meyriat explica que o documento por intenção é produto de ao menos dois sistemas, aquele que produz o objeto e aquele que emite a informação inscrita sobre esse objeto, chamando a atenção para o risco de uma ambiguidade para a compreensão deste termo (2006, p. 13). Por fim, sintetiza sua análise sobre o documento por intenção do seguinte modo: o documento não é um simples veículo da informação, antes interagindo com a mesma já que lhe é consubstancial, ou seja, seu elemento constituinte; o documento possui um autor que não pode ser ignorado e que tem uma intenção de comunicar que se traduz no objetivo atribuído ao documento; esse autor é um ser social que, na sociedade em que vive tem muitos papeis que podem, cada qual, imporlhe limitações diferentes; e todo documento se inscreve em um sistema específico da comunicação, que visa um objetivo próprio (2006, p. 26).

Considerando o documento como um objeto que significa, podemos falar em ao menos três níveis de significação: a produção dos documentos com intenção informativa ou a partir de objetos que não foram criados com esta intenção; as propostas de significação pelos documentalistas sobre aqueles documentos a um público; e a significação que ocorre no processo de apropriação da informação realizada pelo usuário. O segundo nível de significação é de responsabilidade do documentalista (em abordagem bibliográfica, arquivística ou museológica) e de outros que realizam direta ou indiretamente os procedimentos documentários de que tratamos. Nos três níveis há processos interpretativos. O primeiro e o segundo níveis de significação são emblemáticos da sociedade mediada em que vivemos, tendo no terceiro nível o objetivo e motivação dos anteriores.

InCID: R. Ci. Inf. e Doc., Ribeirão Preto, v. 7, n. esp., p. 41-64, ago. 2016. 
Para uma maior compreensão do documento no contexto do campo, recorremos à distinção entre os dois primeiros nível de significação do documento e o terceiro, acima descritos. Como tratamos em Lara e Ortega (2012, p. 381), “a abordagem linguísticosemiótica permite propor o documento como signo, um objeto que tem forma e conteúdo (HJELMSLEV, 1975), que representa algo para alguém, sob algum aspecto ou capacidade (PEIRCE, 1977)". Enquanto signo, o documento é uma construção, uma leitura do real sob determinada perspectiva. A leitura do objeto que o transforma em documento para o sistema segue uma política de informação que privilegia perspectivas institucionais e comunidades discursivas potenciais. O documento é tornado pertinente a partir da seleção, da descrição formal e da atribuição de descritores ou outras unidades de classificação e indexação, enquanto atividades de organização da informação, as quais são seguidas dos demais procedimentos documentários. As atividades documentárias são resultado de uma série de escolhas pois os documentos são organizados em categorias por meio de aspectos que são priorizados frente a outros, implicando uma construção que é permeada de elementos ideológicos (LARA ; ORTEGA, 2012, p. 381-382).

Mas, a interpretação realizada pelos usuários é outro momento: ela é influenciada pelas mensagens propostas por meio de procedimentos documentários sobre objetos, mas não é determinada por elas. Não há relação de correspondência direta entre as mensagens sobre objetos e sua interpretação mas, o estudo das diversas apropriações realizadas pelos usuários (ou não realizadas) contribui como modo de avaliar e reorientar os procedimentos documentários. Por outro lado, as reflexões francesa e espanhola sobre o documento, de que tratamos, salientam a recepção. Ao considerar o processo de comunicação, tem-se que o documento é um produto de uma relação que envolve emissor, interlocutor e contexto. Um objeto é um documento apenas se considerado o mapa de configurações a partir dos quais ele pode tomar forma fazendo sentido para alguém (LARA ; ORTEGA, 2012, p. 385). 
O conceito de documento em abordagem bibliográfica segundo as disciplinas constituintes do campo

\section{Entre a construção empírica e científica do documento}

Os objetos sobre os quais procedimentos de seleção, ordenação, representação e preservação são realizados tiveram sua conceituação construída no tempo no contexto das práticas em que estes procedimentos ocorriam. Segundo o pesquisador mexicano Miguel Ángel Rendón Rojas (2005, p. 134-136), a palavra biblos, em seu sentido original no pensamento grego e helenista, designava o material com que eram fabricados os objetos sobre os quais se escrevia, passando, depois, a indicar os próprios objetos. Esses objetos eram rolos de papiro ou pergaminho (na Antiguidade) e códices (na Idade Média), pois ainda não existiam os livros produzidos pela imprensa como conhecemos hoje. Segundo Rendón Rojas, a palavra biblos era adotada no sentido de objetos com informação objetivada, feitos para serem lidos, portanto, objetos de conservação e transmissão de informação. O autor afirma haver uma certa subestimação do sentido histórico da palavra biblos e suas palavras derivadas, como biblioteca e Bibliotecología (de acordo com o uso na América Espanhola), e que a palavra pode ser interpretada como documento (no sentido abarcador que definimos aqui), ou seja, incluindo não só o livro em seu sentido contemporâneo, enquanto objeto de determinada forma e elementos que o estruturam, mas todo tipo de objeto operado segundo fluxos informativos por meio de sistemas e atividades específicas.

A ideia de um objeto ao qual se atribuía valor cultural era motivo para sua coleta, preservação, ordenação e representação, práticas essas realizadas desde os primeiros ensaios de acervos coletados. Assim, podemos dizer que a prática documentária realizada durante séculos tinha no seu cerne uma conceituação de documento, a partir da qual, tanto no âmbito da consolidação da Bibliografia quanto da Biblioteconomia, de meados do século XIX ao XX, alguns tipos de objetos passaram a ser eleitos como documentos.

Na Bibliografia, o livro é central, embora os objetos de registro que o precederam também sejam considerados. Dois enfoques predominaram em seu desenvolvimento e consolidação durante o século XIX, segundo Araújo (2015, p. 120): o primeiro associado à produção e difusão de instrumentos de registro, adotados na mediação da cultura escrita, como os inventários, catálogos e bibliografias produzidos na era manuscrita e impressa; e o segundo ocupado com o estudo da fisicalidade do livro, quanto aos seus aspectos intrínsecos (relacionados à produção editorial) e aos seus aspectos extrínsecos (no que tange aos exemplares produzidos e às intervenções dos leitores), considerando a ideia de que a forma determina seu sentido e seus modos de apropriação. Segundo o autor, trata-se, 
respectivamente, de uma Bibliografia bibliotecária e de uma Bibliografia material. Balsamo (1998, publicado originalmente em 1984) considera a Bibliografia um dos campos da atividade do complexo sistema de comunicação social, cujo surgimento relaciona-se à formação de bibliotecas abertas ao público, nas quais diferentes cânones bibliográficos encontraram aplicação (p. 11 e 13). Tratando dos desenvolvimentos tecnológicos e sua influência no fazer bibliográfico e na concepção da disciplina, Balsamo discorre sobre a invenção da imprensa até a era da tecnologia eletrônica, a qual teria causado mudanças tão profundas que deram a impressão de uma interrupção da tradição bibliográfica quando, de fato, mudaram apenas os instrumentos e os modos de elaborar e recuperar a informação (p. 14). O autor afirma, no entanto, que mudanças significativas ocorreram com a Bibliografia. Durante o século XX, em função da dificuldade de controlar o crescimento exponencial da produção e do surgimento de documentos diferentes do livro, da revista e do periódico, o primeiro perdeu a centralidade que teve durante séculos, embora não de modo absoluto, levando a que a Bibliografia entrasse em crise. Para Balsamo, atualmente, a Bibliografia continua exercendo seu papel por meio de outras formas nascidas dela, como os abstracts adotados no controle bibliográfico temático, além de permanecer como mecanismo da memória secundária da informação (p. 14-16).

Na Biblioteconomia, a lista de objetos adotados é amplificada para outros tipos de escritos, mas também audiovisuais, entre outras tipologias documentais, ainda que a primazia do livro permaneça, refletindo seu papel no registro do conhecimento. Quanto aos tipos de objeto privilegiados, a consulta à literatura técnica e aos manuais é um caminho para sua identificação, uma vez que, neles, encontra-se arrolada a lista de recursos ou fontes informacionais adotadas, seguida de algum tipo de caracterização em nível formal e da prescrição proposta para sua descrição. Outra possibilidade é a observação empírica que permite identificar as soluções realizadas pelos bibliotecários frente às demandas sociais, as quais demonstram o tratamento de objetos diversos em termos tipológicos e de suporte, refletindo a complexa sociedade em que vivemos. A consolidação da Biblioteconomia pode ser identificada no século XIX até meados do XX, período em que se deu de modo mais efetivo a sistematização dos procedimentos na forma de manuais e outros textos, quais sejam, os de ordenação de documentos em bibliotecas e os de produção de catálogos de seus acervos. Assim, a disciplina se constituiu a partir de procedimentos realizados no âmbito de espaços denominados bibliotecas, de tal modo que a biblioteca marca empiricamente sua identificação.

InCID: R. Ci. Inf. e Doc., Ribeirão Preto, v. 7, n. esp., p. 41-64, ago. 2016. 
Os modos de produção de bibliografias influenciaram a catalogação em bibliotecas, já que estes espaços funcionaram como aplicação dos métodos da Bibliografia. Os conteúdos específicos da Bibliografia foram perdendo terreno mas, boa parte deles foi incorporada, de algum modo, à Biblioteconomia, como ocorreu nos cursos de graduação no Brasil, e são presentes nos sistemas de informação científica.

A Documentação, proposta na passagem do século XIX para o XX, apoia-se na Bibliologia e recoloca a Bibliografia e a Biblioteconomia, considerando os avanços das duas. Base desta proposta é a ideia de abrangência para todo e qualquer objeto como passível de ser abordado como documento, posteriormente desenvolvida por meio da busca pela explicitação das condições em que ocorre a mudança de estatuto de objeto a documento. O termo documento passa a ser adotado para indicar o objeto que é eleito para a execução dos procedimentos - sendo essa escolha o primeiro procedimento que lhe é imputado -, mas é propriamente o produto destes procedimentos, por este motivo, chamados de procedimentos documentários. No decorrer do século XX, o termo foi desenvolvido em solo europeu sob a incorporação dos conceitos de informação e comunicação e do reconhecimento dos métodos da Documentação para uma compreensão do documento. Os estudos de linguagem passaram a ser adotados para uma fundamentação e operacionalização dos métodos documentários, na perspectiva de que os procedimentos e os instrumentos devem conduzir a um processo de significação que objetiva a comunicação. Recursos tecnológicos também são explorados nos Congressos de Documentação e nas diversas publicações em nome desta disciplina, na primeira metade do século XX, envolvendo microfilmagem, técnicas de reprografia e mecanização da busca de documentos.

O conjunto de ideias organizadas sob o nome Ciência da Informação, proposto nos Estados Unidos, em meados do século XX, predominou frente a movimentos semelhantes ocorridos na Europa central e oriental, no mesmo período, que apresentaram outros vieses devido à influência da Documentação nestes países (LÓPEZ YEPES, 1995, como tratamos em ORTEGA, 2009, p. 14). Na proposição inicial da Ciência da Informação estadunidense, o termo documento construído na Europa não foi considerado. Fondin (2005) trata dessa orientação predominante da Ciência da Informação, afirmando que o interesse de pesquisadores em técnicas de tratamento, armazenamento, busca e difusão de documentos e seus conteúdos para fornecer informação a um certo público partiu para uma abordagem mais global sobre informação que acabou por gerar indefinição e ambiguidade. Considera que as contradições são evidentes na pesquisa em Ciência da Informação atual e explicam as 
divergências de pontos de vista expressos por um número cada vez maior de pesquisadores da disciplina. A partir deste quadro, Fondin pergunta qual especificidade científica a Ciência da Informação reivindica em torno do objeto informação, uma vez que ela não pode pretender estudar igual e simultaneamente o sistema primário e o sistema secundário de produção e difusão da informação, ou seja, respectivamente, as ações desenvolvidas por autores e leitores e as ações de mediação de que se ocupam os documentalistas. Fondin explica que se trata de dois fenômenos nitidamente distintos, embora relacionados, de tal modo que não se pode justapor estes fenômenos e seus sistemas correspondentes apenas por serem dependentes cronologicamente e possuírem em comum o documento em sua materialidade.

Atualmente, o termo documento é estudado na literatura em inglês, de maior abrangência territorial, no campo nomeado Ciência da Informação, ou Biblioteconomia e Ciência da Informação (LIS-Library and Information Science). Os autores pioneiros da Documentação, Paul Otlet e Suzanne Briet, são retomados, mas não os autores franceses posteriores, como Robert Escarpit e Jean Meyriat, entre outros, que contribuíram para consolidar o conceito a partir da década de 1980. Autores contemporâneos colocam o tema na pauta das discussões realizadas nas pesquisas sobre Ciência da Informação, algumas vezes na perspectiva mais ampla da produção e uso da informação, outras vezes, no sentido estrito das ações de mediação documentária. A dicotomia de orientações permanece como problema, já que relações entre elas não são estabelecidas. No Brasil, o nome Ciência da Informação foi institucionalizado para as atividades de ensino em nível de pós-graduação e de pesquisa, nas quais os aportes das disciplinas citadas anteriormente são discutidos, já que elas são emblemáticas da constituição dos conceitos, do processo e da função do campo.

Buckland é um dos responsáveis por disseminar as contribuições de Otlet e Briet em idioma inglês. Além de escrever sobre Suzanne Briet, a quem denominou Madame Documentation, explicita que Otlet enfatizou a necessidade de uma definição de documento que incluísse objetos naturais, artefatos, objetos apontando pistas de atividades humanas, objetos tais como modelos designados para representar ideias, e obras de artes, assim como textos. Mais que isso, Buckland está entre os autores que desenvolveram e atualizaram o pensamento aqui apresentado. Frente à pergunta 'o que é informativo?', o autor sugere inverter a raciocínio usual perguntando às pessoas o que elas identificam como coisas a partir das quais elas podem tornar-se informadas. $\mathrm{O}$ autor sugere 'discurso' como um termo melhor para indicar textos no sentido geral ou artefatos com intenção de representar coisas. Apresenta como possibilidade dividir objetos em: artefatos com intenção de constituir discurso (como 
livros), artefatos que não tinham esta intenção (como barcos), e objetos que não são artefatos (como os antílopes). Do mesmo modo que Meyriat e outros pesquisadores franceses, Buckland apresenta exemplos explicativos dos objetos e suas funções posteriores, como no caso do livro que pode ser usado como um peso para portas (1991, p. 43, 44, 46 e 47).

Em Ciência da Informação, a imprecisão em torno do objeto eleito - a informação pouco agregou à construção conceitual do documento; a proposta da Documentação não foi fortemente disseminada em função do fortalecimento da produção científica dos Estados Unidos, simultaneamente ao esquecimento dos estudos europeus do pós-Guerra e da menor proficiência por pesquisadores de leitura em francês; e a Bibliografia foi grandemente absorvida pela Biblioteconomia. Esta, por sua vez, manteve a perspectiva de um objeto concebido empiricamente, contribuindo para a indicação de um conceito, a despeito das restrições de fundamentação que lhe são típicas. Considerando que a imprecisão desenvolvida na pesquisa em Ciência da Informação não encontra respaldo no conhecimento já consolidado e reconhecido advindo das práticas de ações de mediação documentária, a perspectiva fornecida pela Biblioteconomia responde pelo pensamento predominante do campo quanto ao objeto empírico com que opera.

No âmbito desse pensamento predominante, o objeto não é propriamente conceituado, mas está implícito na literatura técnica e nas práticas. Dito de outro modo, o objeto eleito não é caracterizado pois, sendo dependente dos modos de produção do conhecimento e das contingências institucionais, ele é colocado a reboque dessas circunstâncias. A questão da circunstancialidade das escolhas dos objetos culturais que marcou a Bibliografia e a Biblioteconomia é aqui considerada no sentido de que estas disciplinas não se constituíram visando contemplar propriamente todas as possibilidades documentais passíveis de oferecer aos sujeitos conteúdos de seu interesse, optando antes pelos tipos de objetos mais usualmente demandados ou significativos a cada tempo.

No entanto, procedimentos têm sido executados com algum nível de objetivação, o que permite identificar alguns critérios bastante razoáveis. Pensato (1994, publicado originalmente em 1987) discorre ricamente sobre os critérios adotados na atividade bibliográfica, em seu livro Curso de Bibliografia. À p. 161, o autor trata das publicações descritas na Bibliografia Nacional Italiana que são, em geral, as monografias e os primeiros números de publicações seriadas; é excluído o material cuja forma se destina a grupos e categorias particulares de pessoas, é de caráter interno ou privado ou que tenha um caráter 
efêmero, assim como todos os materiais que não são livros. $\mathrm{O}$ autor apresenta ainda uma lista de 25 tópicos de publicações não descritas nesta bibliografia nacional. Há uma objetivação de critérios baseada no interesse de uso por públicos mais amplos e, de algum modo, na lista negativa de objetos, não ficando claro o significado da exclusão do material que não é livro, embora o critério considerado também neste caso possa ser o uso por grupos menores. Como vimos, Balsamo, ao discorrer sobre a Bibliografia, entende que o apoio sobre o objeto livro contribuiu fortemente para o enfraquecimento da disciplina, haja vista que outros tipos de documento se fizeram presentes, com implicações nos modos de produção, representação, acesso e uso.

Quanto a isso, Meyriat (1981, p. 60) fala que os bibliotecários anglo-saxões criaram o termo 'não-livro' (non-book) para designar todos os bens que são confiados a seus cuidados, mas que eles não sabem como catalogar ou armazenar, como discos, diapositivos e fitas magnéticas, desenvolvendo até uma norma de descrição bibliográfica para eles. Observa que definições negativas e baseadas na exclusão não são funcionais, pois se trata de um falso conjunto e os elementos agrupados deste modo não têm nada em comum além de serem cobertos pelo mesmo rótulo, o que leva a que o conjunto seja reduzido com o tempo quando um ou outro de seus elementos ganha importância suficiente para receber um discurso e um tratamento próprios.

Situação similar à circunstancialidade das tipologias documentais ocorre, tanto em Biblioteconomia, quanto ao que podemos ainda chamar de Bibliografia, nos cursos de graduação brasileiros. Trata-se da prevalência da normatividade como orientadora do processo de ensino-aprendizagem, nem sempre amparado pela contextualização da norma, por um sistema conceitual e por metodologias que sustentem o procedimento em questão. Em Biblioteconomia, em função da grande disseminação do modelo dos Estados Unidos de trabalho em bibliotecas, o AACR2 (Anglo-American Cataloguing Rules, 2. ed.) costuma funcionar como instrumento padrão para o ensino da produção de catálogos de bibliotecas, cuja prescrição tem como base o documento livro, em função do qual outros tipos de documentos são desenvolvidos. Entre esses outros tipos de documentos, a exemplo dos nonbooks, é usual contemplar o ensino de catalogação dos chamados 'materiais especiais'. Em Bibliografia, a produção de referências bibliográficas também é trabalhada essencialmente na forma do ensino do uso de normas, em especial a brasileira (Associação Brasileira de Normas Técnicas-ABNT). As orientações normativas para a produção de referências em um trabalho acadêmico e os modos de normalizá-lo compõem, junto com a apresentação de fontes 
O conceito de documento em abordagem bibliográfica segundo as disciplinas constituintes do campo

bibliográficas, impressas e eletrônicas, os conteúdos herdados das antigas disciplinas de Bibliografia. Ainda que outras disciplinas com enfoque tecnológico ampliem os tipos de objetos e as estruturas de representação para além dos catálogos de biblioteca e do modelo comumente adotado em seu ensino, a diversidade de repertórios bibliográficos não é contemplada devidamente, já que não se trata apenas de apresentar tipos de repertórios, mas de formar o aluno quanto aos conceitos operacionais que os sustentam, desenvolvendo recursos cognitivos que permitam responder às diversas demandas sociais por informação. Assim, também nos currículos, observamos a necessidade de elaboração de modelos generalizáveis que superem o treinamento a partir de um ou outro modelo, segundo o pensamento predominante de base normativa.

\section{O documento em abordagem bibliográfica, arquivística e museológica}

Como tratamos anteriormente (ORTEGA, 2016, p. 6-9), documentos são objetos abordados informacionalmente. O documento se define por uma instância física (seu suporte material) e uma instância simbólica (informativa, conteudística), sendo que esta última é sempre uma atribuição, ou seja, não é inerente ao objeto. A dimensão informativa do documento não é prévia, é construída no momento da interpretação. Se o documento é objeto construído, ou seja, não existe a priori, ou in natura, o documento bibliográfico também não é objeto pré-existente, mas depende de ações de significação que o tornem como tal.

Cabe recolocar o pensamento que atribui certas tipologias documentais como definidoras do documento bibliográfico, como o livro e o periódico, embora eles sejam recorrentes em bibliotecas, centros de documentação e bases de dados especializadas, entre outros, por apresentarem conteúdos científicos ou literários. Outra revisão necessária é a da ideia de que o suporte alteraria a tipologia documental: um livro, por exemplo, ao apresentar uma mensagem condicionada por uma forma de organização de conteúdos que lhe caracteriza, continua sendo um livro, seja em papel, seja em meio eletrônico (ORTEGA, 2016, p. 9).

Buscando caracterizar a informação bibliográfica, podemos dizer que ela contempla: a informação para construção de conhecimento, necessária a atividades educacionais, científicas e profissionais; a informação para fruição ou experiência estética; e a informação para fins utilitários, relativa ao acesso a serviços ou atividades de entretenimento, educação, cultura, saúde e direitos civis. Além dos aspectos cognitivos, a abordagem bibliográfica envolve a 
experiência sensorial sobre objetos, como aquelas propostas a partir de exposições (ORTEGA, 2016, p. 6-7).

Assim, para uma maior compreensão do documento em abordagem bibliográfica, a exploração das abordagens arquivística e museológica permite identificar distinções, em torno das quais características comuns apresentam-se como fundamentais ao conceito. As operações sobre objetos transformando-os em documentos diferenciam-se quanto ao tipo de olhar realizado, o qual é definido segundo interesses socialmente constituídos que são concretizados em contextos institucionais correspondentes. Para Johanna Smit (2000b, p. 125), as expressões 'informação bibliográfica', 'informação arquivística' e 'informação museológica' ressaltam o termo 'informação' e se diversificam, a partir da raiz comum, por atributos que as especificam, baseados nos tipos de utilização destas informações. Os procedimentos documentários do tipo bibliográfico, arquivístico e museológico apresentam, cada qual, características próprias e exclusivas, uma em relação à outra, sob certa configuração comum que as congrega.

As características comuns destes três tipos de abordagens sobre documentos são mais acentuadas em um aspecto que em outro, apontando para suas diferenças, como na ideia proposta por Homulos (1990), e tratada por Smit (1993), referindo-se à relação de continuidade entre as instituições arquivo, museu e biblioteca, consideradas instituições coletoras de cultura. Posteriormente, Smit (2000a, p. 31) apontou para o problema da ênfase no acervo como forma de elaborar as distinções e relações citadas. De fato, a ideia de instituições referenciadoras de objetos, cujos processos permitem sua comunicação a públicos específicos, aproxima-se da função social do campo de que tratamos, mais que a ideia de instituições coletoras de cultura. Além disso, estas características comuns e distintas podem ser consideradas a partir das instituições fundamentais do campo - biblioteca, arquivo e museu -, mas não reduzidas a elas, já que estas denominações não contemplam todos os ambientes em que as atividades em questão são ou podem ser desenvolvidas. Os procedimentos documentários de ordem bibliográfica ocorrem em bibliotecas, centros de documentação e centros de memória, na produção de bibliografias nacionais e de bases de dados científicas, nos sistemas de informação ao cidadão, nos estudos bibliométricos, na gestão da produção de revistas eletrônicas, nos portais de informação da Internet, entre outros. Temos de fato sistemas bibliográficos a partir dos quais serviços e ações diversas de promoção do uso qualificado da informação são realizados. Tomando em conta o conceito de biblioteca, e não o espaço físico que recebe este nome (o qual não é seu traço definitório), a 
O conceito de documento em abordagem bibliográfica segundo as disciplinas constituintes do campo

relação com a Bibliografia contribui em função das ideias de coleção e de repertório da coleção. Faz-se necessário fazer o mesmo exercício com os conceitos de arquivo e de museu.

Assim, os documentos são informações selecionadas e organizadas materialmente em um sistema, cuja significação proposta objetiva orientar processos de significação pelo público. O modo diverso como essas informações são operadas em sistemas demonstra a plasticidade do documento, como podemos observar pela identificação dos seguintes produtos documentários na forma de objetos e seus registros: objetos abordados como documentos; registros que representam estes documentos em sua totalidade, em seu conjunto, ou em suas partes; registros (cadastrais, estatísticos) constituídos a partir de documentos diversos; e registros constituídos a partir de transações (ou seja, operações administrativas). Os sistemas produzidos referem-se a tipos de processos que realizam o controle de processos administrativos, no caso da Arquivologia de fase corrente, ou a representação de informações visando recuperação, quando se refere à Biblioteconomia, à Museologia e à Arquivologia de fase permanente.

Os objetos tomados como documentos podem ser - nos três casos - objetos utilitários ou estéticos, assim como textos, materiais audiovisuais, objetos ou ambientes da natureza, edificações, pessoas etc. Como vimos, está em questão a produção de significação sobre o objeto original, a partir de suas características diversas (físicas, de identificação, contextuais etc.) quanto a este novo lugar simbólico em que é colocado, de modo que tanto o objeto quanto suas representações tornam-se documentos.

Os modos peculiares de produção e uso de documentos pelas pessoas correspondem às três abordagens de que tratamos, e são ressignificados por procedimentos documentários específicos que visam apropriação da informação. Assim, propomos a seguinte sistematização:

- abordagem bibliográfica: procedimentos documentários com fins científicos, estéticos, educacionais, profissionais, utilitários, de lazer, outros, baseadas em ações e reflexões humanas. É a abordagem que mais recebeu estudos sob o ponto de vista informacional, mas, paradoxalmente, a mais difícil de definir.

- abordagem arquivística: procedimentos documentários realizados no contexto da vida de uma pessoa ou de uma organização, com fins de gestão, depois fins científicos, estéticos, educacionais, profissionais, utilitários, de lazer, outros. 
- abordagem museológica: procedimentos documentários sobre objetos vistos como representativos de sociedades, de instituições, da natureza, com fins científicos, estéticos, educacionais, profissionais, utilitários, de lazer, outros.

Considerando as três abordagens, segue sua caracterização segundo as categorias documento por intenção e documento por atribuição.

Ao tratar dos documentos de arquivo, Marie-Anne Chabin (1999, p. 67-69) fala em arquivo de nascença e arquivo por batismo. O documento, em sua primeira fase, 'nasce' no contexto da atividade da vida de uma pessoa ou instituição, em que exerce valor de prova ou valor utilitário, por isso constituindo documentos de nascença. Os arquivos por batismo, por sua vez, apresentam duas origens, sempre relativas a um valor de memória que lhes é atribuído: arquivos de nascença que deixaram de ter utilidade para seu produtor podem passar por um 'renascimento'; e documentos desprovidos de valor utilitário ou de prova, portanto, que não pertencem nem pertenceram a arquivos de nascença, mas que recebem valor de testemunho. A autora afirma que o arquivo de nascença é um conjunto coerente de documentos que permite apreender com mais rigor seu conteúdo, enquanto o arquivo batizado é frequentemente um documento isolado, cujo contexto de criação é mais difícil de restituir. Considerando que os arquivos de nascença são constituídos por documentos de nascença, podemos falar também em documentos por batismo. A partir daí, parece pertinente equiparar os documentos de nascença à categoria documento por intenção, enquanto tanto os documentos de nascença como os por batismo o são de fato apenas se por atribuição.

Em Museologia, o processo de musealização é por excelência uma reflexão sobre o documento por atribuição, ao enfatizar que a função original não é em si o que está em questão, mas sim a sua representação em outro contexto. Para Desvallés e Mairesse (2013, p. 57), a musealização é processo científico que compreende o conjunto das atividades de seleção, conservação, catalogação, exposição, publicações etc.

Na abordagem arquivística, os documentos de nascença são documentos por intenção, mas na museológica, não parece haver documentos por intenção, a não ser que consideremos, por exemplo, os objetos construídos especificamente para compor os museus virtuais. $\mathrm{Na}$ abordagem bibliográfica, de modo semelhante à abordagem arquivística, os documentos por intenção são usuais (mas não os únicos), porque estão em evidência neles, o conteúdo, no primeiro caso, e as condições orgânicas de produção, no segundo. No entanto, se todo 
O conceito de documento em abordagem bibliográfica segundo as disciplinas constituintes do campo

documento depende de sua atribuição como tal, um documento será efetivamente bibliográfico, arquivístico ou museológico a depender de receber uma destas atribuições.

Como a tipologia e suporte documentais não são determinantes para que objetos sejam bibliográficos, arquivísticos ou museológicos, uma biblioteca escolar, por exemplo, pode constituir sua coleção com livros, revistas, quadrinhos, mas também com brinquedos, como carrinhos, bonecas e jogos. Isso significa dizer que estes objetos estão funcionando bibliograficamente, ou seja, com função informacional pedagógica, seja cognitiva, lúdica ou estética. Cada uma destas peças, para uso devido no trabalho de professores, bibliotecários ou outros, deve ser registrada, representada, ordenada e conservada. Vale lembrar que o AACR2, amplamente adotado em bibliotecas, contempla regras de descrição para objetos tridimensionais, a despeito da ausência de literatura que sustente as prescrições que o compõem.

Meyriat debruçou-se sobre os documentos por intenção, atribuindo explicitamente à Documentologia o seu estudo. Como dissemos, o autor chamou a atenção para a categoria documento por intenção, distinguindo a intencionalidade na produção do documento (que explica esta categoria) e a intencionalidade inerente à produção de mensagens documentárias. Smit (2008, p. 12) discorre sobre o que entende como os dois movimentos mais marcantes do campo em torno do documento: Jesse Shera, na década de 1970, limitou o documento a um registro gráfico, em especial o textual, mas incluindo os documentos audiovisuais, com ênfase ao caráter intencional do documento, como o entendemos hoje; 40 anos antes Otlet afirmou considerar praticamente tudo um documento, observando menos sua materialidade e mais a sua função, e relacionando essa função à expressão do conhecimento humano. A perspectiva adotada por Shera é pragmática, caracterizando-se pela intencionalidade fornecida aos documentos em sua produção e uso, segundo o que chamamos de perspectiva empírica. Otlet baseia-se na funcionalidade, do que decorre o objetivo de apropriação pelas pessoas por meio da intencionalidade impressa às mensagens documentárias. Em Shera, o foco está no objeto produzido para ser documento, e em Otlet (e em especial nos autores posteriores), o foco está nas mensagens documentárias, portanto, em qualquer objeto quanto a sua possibilidade de 'vir-a-ser' um documento.

Como dissemos, a Biblioteconomia e a Bibliografia, assim como a Arquivologia, são casos privilegiados de documentos por intenção, mas o sentido (não o termo) de documento por intenção é recorrentemente adotado para caracterizar os documentos nestas disciplinas. 
Trata-se de definição parcial construída empiricamente, na prática e em manuais e outros textos técnicos. Documento por intenção é denominação permanente quanto ao objeto a que se refere, já que se trata de característica relativa à sua produção. No entanto, não se pode equivaler documentos bibliográficos e arquivísticos a documentos por intenção.

\section{Considerações finais}

Faz-se necessário explicitar aspectos essenciais do percurso do objeto ao documento, distinguindo-os dos aspectos contingenciais das práticas institucionais que foram cristalizados na literatura técnica e não são suficientes para uma construção do conceito de documento. Práticas de coleta, ordenação, representação e preservação de objetos, em função de serem valorizados culturalmente, foram realizadas, em especial, a partir do desenvolvimento da escrita. Deste modo, empiricamente, houve o reconhecimento do valor do objeto a ser selecionado e a compreensão de que os procedimentos produzem mensagens que dizem algo sobre ele para um público.

No entanto, o pensamento que prevaleceu até início do século $\mathrm{XX}$, e que ainda é predominante no campo, não contou com parâmetros científicos suficientes que sustentassem o conceito de documento. De fato, tornou-se mais amplamente conhecida a perspectiva em que prevalece a instância tipológica do objeto e normatizadora de sua descrição, menos que a perspectiva baseada no caráter simbólico dos procedimentos e, portanto, de seu produto final. O segundo implica conceito de documento que decorre da construção de uma significação e o primeiro considera que certos objetos são documentos a priori. Essa diferença deflagra olhares distintos sobre esse objeto empírico e sobre o significado dos procedimentos realizados sobre ele. Estudos sobre estes procedimentos são necessários a uma compreensão, não apenas do conceito de documento, mas do campo.

Desse modo, a questão desse trabalho não se coloca quanto a uma desconsideração da construção empírica do campo sobre o documento - uma vez consideradas as significativas práticas profissionais e o relevante material técnico produzido - mas quanto às reflexões que ela merece receber para uma construção científica. Quando, em Documentação, entendeu-se que todo objeto é válido para 'vir-a-ser' um documento, mais que o objeto em si, foi evidenciado o papel dos procedimentos sobre eles frente ao objetivo de apropriação da informação. Nesta disciplina, a construção do conceito de documento chama a atenção pela 
O conceito de documento em abordagem bibliográfica segundo as disciplinas constituintes do campo

elaboração coerente e continuada no tempo. A questão é a da secundarização do pensamento do campo que se ocupou de fundamentar a noção de documento e de desenvolver metodologias rigorosas baseadas na compreensão do caráter simbólico dos procedimentos e as implicações do menor reconhecimento destes estudos para uma consolidação científica do campo. Afinal, não se pode esquecer que as disciplinas tratadas aqui se explicam uma pela outra porque partem ou decorrem delas, aproveitando seus avanços e equívocos, embora o percurso tenha ocorrido em grande medida na forma de assimilação arbitrária e de rupturas improdutivas.

\section{Referências}

ARAÚJO, A. V. F. Pioneirismo bibliográfico em um polímeta do séc. XVI: Conrad Gesner. Informação \& Informação, Londrina, v. 20, n. 2, maio/ago. 2015. [Número Temático: I Seminário Internacional "A Arte da Bibliografia: ferramentas históricas, problemas metodológicos e práticas contemporâneas"]. Disponível em:

<http://www.uel.br/revistas/uel/index.php/informacao/article/view/23127/pdf_62 >. Acesso em: 23 jul. 2016.

BALSAMO, L. La bibliografía: historia de una tradición. Gijón: Trea, 1998.

(Biblioteconomía y Administración, 20). Publicado originalmente em italiano em 1984.

BRIET, S. Qu'est-ce que la documentation? Paris: Édit, 1951. 48 p. Disponível em: $\langle$ http://martinetl.free.fr/suzannebriet/questcequeladocumentation/briet.pdf $>$. Acesso em: 23 jul. 2016.

BUCKLAND, M. Information and information systems. New York: Praeger, 1991.

CHABIN, M. A. Naissance et baptême des archives. In: . Je pense donc j'archive:

l'archive dans la societé de l'information. Paris: L'Harmattan, 1999. p. 67-69.

COUZINET, V.; RÉGIMBEAU, G.; COURBIÈRES, C. Sur le document: notion, travaux et propositions. In: COUZINET, V.; RAUZIER, J. M. (Col.). Jean Meyriat, théoricien et praticien de l'information-documentation. Paris: ADBS, 2001. p. 467-506.

DESVAllÉS, A.; MAIRESSE, F. (Eds.). Conceitos-chave de Museologia. São Paulo: ICOM; Armand Colin, 2013. Disponível em: $<$ http://icom.museum/fileadmin/user_upload/pdf/Key_Concepts_of_Museology/ConceitosChavedeMuseologia_pt.pdf>. Acesso em: 23 jul. 2016.

ESCARPIT, R. L'information et la communication: théorie générale. Paris: Hachette Superiour, 1991. 222 p. (Hachette Université Communication). Inicialmente publicado em 1976 pela mesma editora.

FAYET-SCRIBE, S. Histoire de la documentation en France: culture, science et technologie de l'information, 1895-1937. Paris: CNRS, 2001. (CNRS Histoire). 
FONDIN, H. La science de l'information ou le pois de l'histoire. Les enjeux de l'information et de la communication. Grenoble, 2005. Disponível em: <http://lesenjeux.ugrenoble3.fr/2005/Fondin/fondin.pdf>. Acesso em: 23 jul. 2016.

HOMULOS, P. Museums to libraries: a family of collecting institutions. Art Libraries Journal, Cambridge, v. 15, n. 1, p. 11-13, 1990.

LARA, M. L. G.; ORTEGA, C. D. Para uma abordagem contemporânea do documento na Ciência da Informação. In: CONGRESO ISKO, 2011. Ferrol. [Anais]. A Coruña: Universidade da Coruña, 2012. p. 371-387. Disponível em: <http://ruc.udc.es/dspace/bitstream/2183/11621/1/CC_132_art_23.pdf >. Acesso em: 23 jul. 2016.

LÓPEZ YEPES, J. La Documentación como disciplina: teoría e historia. 2. ed. Pamplona: Ediciones Universidad de Navarra (EUNSA), 1995. 337 p.

MEYRIAT, J. Document, documentation, documentologie. Schéma et Schématisation, Paris, $2^{\circ}$ trimestre, n. 14, p. 51-63, 1981.

MEYRIAT, J. Pour une compréhension plurisystémique du document (par intention).

Sciences de la Societé, Toulouse, n. 68, mai 2006, p. 11-28. (Dossiê "Dimensions sociales du document", coord. por Caroline Courbières e Gérard Régimbeau).

ORTEGA, C. D. A documentação como uma das origens da ciência da informação e base fértil para sua fundamentação. Brazilian Journal of Information Science, Marília, v. 3, n. 1, p. 3-35, jan./jun. 2009. Disponível em: <http://www2.marilia.unesp.br/revistas/index.php/bjis/article/view/48/263 > . Acesso em: 23 jul. 2016.

Ordenação de documentos como processo de organização da informação. In:

ORTEGA, Cristina Dotta; SILVA, Camila Mariana Aparecida da; SANTOS, Marcelo Nair dos. Ordenação de documentos na atividade bibliotecária. Brasília: Briquet de Lemos, 2016. 146 p. p. 6-14. Disponível para compra em:

$<$ http://www.briquetdelemos.com.br/ordenac-o-de-documentos-na-atividade-bibliotecariabaixar-em-pdf.html>. Acesso em: 23 jul. 2016.

.; LARA, M. L. G. A noção de documento: de Otlet aos dias de hoje. Datagramazero, Rio de Janeiro, v. 11, p. 3, 2010. Disponível em:

<http://www.brapci.ufpr.br/brapci/index.php/article/view/0000008400/cca9a49474077340b06 9f1222c313618>. Acesso em: 3 jul. 2016.

OTLET, P. EI Tratado de Documentación: el libro sobre el libro: teoría y práctica. Trad. por Maria Dolores Ayuso García. Murcia: Universidad de Murcia, 1996.

Traité de Documentation: le livre sur le livre: théorie et pratique. Bruxelles: Mundaneum, 1934. Disponível em: 〈http://lib.ugent.be/fulltxt/RUG01/000/990/276/BIB038A006_2006_0001_AC.pdf>. Acesso em: 23 jul. 2016.

PENSATO, R. Curso de Bibliografia. Gijón: Trea, 1994. (Biblioteconomía y Administración, 4). Publicado originalmente em italiano em 1987. 
RENDÓN ROJAS, M. Á. Bases teóricas y filosóficas de la Bibliotecología. 2. ed. México: UNAM, Centro Universitario de Investigaciones Bibliotecológicas, 2005. (Sistemas bibliotecarios de información y sociedad).

\section{SAGREDO FERNÁNDEZ, F.; IZQUIERDO ARROYO, J. M. Concepción lógico-} lingüística de la Documentación. Madrid: IBERCOM, 1983.

SMIT, J. W. A documentação e suas diversas abordagens. In: GRANATO, M.; SANTOS, C. P.; LOUREIRO, M. L. N. M. (Orgs.). Documentação em museus. Rio de Janeiro: MAST, 2008. (MAST Colloquia, 10). p. 11-22. Disponível em:

<http://www.mast.br/livros/mast_colloquia_10.pdf>. Acesso em: 23 jul. 2016.

Arquivologia, Biblioteconomia e Museologia: o que agrega estas atividades profissionais e o que as separa? Revista Brasileira de Biblioteconomia e Documentação, São Paulo, Nova Série, v. 1, n. 2, p. 27-36, 2000a.

O documento audiovisual ou a proximidade entre as 3 Marias. Revista Brasileira de Biblioteconomia e Documentação, São Paulo, v. 26, n. 1-2, p. 81-85, 1993.

O Profissional da Informação e sua relação com as áreas de

Biblioteconomia/Documentação, Arquivologia e Museologia. In: VALENTIM, M. L. P. (Org.). Profissionais da Informação: formação, perfil e atuação profissional. São Paulo: Polis, 2000b. p.119-134. 